\title{
O ENFOQUE CTS NOS CURSOS DE LICENCIATURA EM CIÊNCIAS DA NATUREZA
}

\author{
Jucelino Cortez ${ }^{1}$ \\ José Claudio Del Pino ${ }^{2}$
}

\begin{abstract}
Resumo: Neste artigo apresentamos o desenvolvimento e os resultados de uma pesquisa realizada junto aos coordenadores de cursos de Licenciatura em Física, Licenciatura em Química e Licenciatura em Ciências Biológicas, de instituiçôes de ensino superior do Norte do Rio Grande do Sul, visando identificar quando e como os acadêmicos destes cursos tem oportunidade de conhecer a abordagem Ciência-Tecnologia-Sociedade no ensino das ciências. Para atingir este objetivo, realizamos um estudo de caso, com entrevistas semiestruturadas, gerando dados que foram tratados pelo procedimento da Análise Textual Discursiva. Norteado pelos referenciais teóricos, apontamos categorias a priori, identificando assim, nos discursos dos entrevistados, alguns pontos que indicam a confluência entre os currículos dos cursos e o enfoque CTS.
\end{abstract}

Palavras-chave: Abordagem CTS. Ensino de Ciências. Licenciaturas.

\section{CTS APPROACH IN THE NATURAL SCIENCES TEACHING DEGREES}

\begin{abstract}
In this article we present the development and results of a research, carried out with the coordinators of the Physics, Chemistry and Biological Sciences teaching degrees from higher education institutions in the North of Rio Grande do Sul, to identify when and how the students of these courses have the opportunity to get to know the Science-Technology-Society (CTS) approach in science teaching. To achieve this goal, we have conducted a case study, with semistructured interviews, generating data which were then treated with the Discursive Textual Analysis procedure. Based on the theoretical references, we point out a priori categories, thus identifying, in the interviewees' discourses, some points that indicate the confluence between the curricula of the courses and the STS approach.
\end{abstract}

Keywords: CTS Approach. Science teaching. Bachelor's degrees.

1 Professor da área de Física do Instituto de Ciências Exatas e Geociências da Universidade de Passo Fundo.

2 Professor do Programa de Pós-Graduação em Educação em Ciência: Química da vida e saúde da UFRGS. 


\title{
INTRODUÇÃO
}

Para introduzirmos a presente pesquisa, nos remetemos, de início, às proposições de António Cachapuz e seus colaboradores, na obra "A Necessária renovação do ensino das ciências" (CACHAPUZ, et al., 2005). Nesta, os autores afirmam que estamos vivendo uma situação chamada de "autêntica emergência planetária", considerando uma realidade associada a sérios problemas como: "contaminação e degradação dos ecossistemas, esgotamento de recursos, crescimento incontrolado da população mundial, desequilíbrios insustentáveis, conflitos destrutivos, perda de diversidade biológica e cultural (CACHAPUZ, et al., 2005, p. 14).

Estes teóricos citam ainda, em uma alusão ao apelo das Nações Unidas, que os atores da educação básica e da educação superior devem prestar atenção a esta problemática.

\begin{abstract}
Necessitamos, pois, de assumir um compromisso para que toda a educação, tanto formal (desde a escola primária até a universidade) como informal (museus, mídia...), preste sistematicamente atenção à situação do mundo, com a finalidade de proporcionar uma percepção correta dos problemas e de fomentar atitudes e comportamentos favoráveis para construir um desenvolvimento sustentável. Deste modo pretende-se contribuir para formar cidadãos e cidadãs conscientes da gravidade e do caráter global dos problemas e prepará-los para participar na tomada de decisões adequadas (CACHAPUZ, et al., 2005, p. 14).
\end{abstract}

No entanto, conforme os mesmos autores citados, a educação oferecida aos nossos educandos não está atingindo este propósito, motivando assim, "reiteradamente o elevado insucesso escolar, assim como a falta de interesse e, inclusivamente, repulsa, que as matérias científicas geram" (CACHAPUZ, et al., 2005, p. 20).

Para a UNESCO, esta preocupante situação, mantida através das décadas, está relacionada, em parte, com as instituições de ensino superior (IES). Para esse órgão, as IES, nos cursos de licenciatura, devem proporcionar condições para a plena formação dos acadêmicos, valorizando as discussões acerca das funções do professor na evolução dos processos de aprendizagem e no seu papel de formador de cidadãos (UNESCO, 2009). Reforçando este compromisso, Cachapuz e seus colaboradores afirmam que, após várias investigações na área de Ensino de Ciências, é possível afirmar que os professores acabam ensinando as ciências, do mesmo modo que eles a concebem (CACHAPUZ, et al. 2004). Assim, percebese a importância das IES e dos cursos de licenciatura na prática pedagógica dos professores da educação básica e, entender como estes cursos funcionam, podem nos ajudar a identificar então a "ciência que eles concebem".

$\mathrm{Na}$ busca de melhorias para o ensino de ciências, Santos (2012), defende que os currículos destas áreas deveriam valorizar mais a formação da cidadania, a contextualização e o uso de temas sociocientíficos. Neste sentido, para este 
teórico, o enfoque Ciência - Tecnologia - Sociedade tem muito a contribuir para a superação da realidade citada.

Então, cientes do papel das licenciaturas e das possibilidades do enfoque CTS, buscamos junto aos coordenadores dos cursos, identificar como estas graduações trabalham e como tratam estas questões relacionadas à formação dos seus acadêmicos. Acreditamos que estes profissionais, devido ao cargo que ocupam, possuem o necessário conhecimento sobre as características de seus respectivos cursos, podendo assim, contribuir para o desvelamento das relações estudadas. Objetivamos, com esta pesquisa, analisar o real funcionamento dos cursos, além do que está exposto no Plano Pedagógico do Curso, buscando quando e como os acadêmicos tem oportunidade de conhecer a abordagem CTS no ensino das ciências.

Para alcançar nosso objetivo, realizamos uma pesquisa de abordagem qualitativa com procedimento de estudo de caso, considerando que procuramos entender, sem intervenção, a realidade de uma região específica, através de informações obtidas com um limitado corpo de sujeitos (GERHARDT E SILVEIRA, 2009). Para esta tarefa, escolhemos o uso de entrevistas semiestruturadas que, depois de realizadas, por meio de gravação de áudio, foram tratadas pelo procedimento de análise textual discursiva (MORAES, 2003), possibilitando assim, reorganizar as informações conforme as categorias escolhidas a priori, consoantes com a abordagem CTS.

Este artigo tem, na sequência, um breve apontamento sobre o referencial teórico, seguido pela descrição da metodologia e, após a indicação destes norteadores, descrevemos as análises das entrevistas e dos resultados, encerrando com as considerações finais.

\section{REFERENCIAL TEÓRICO}

Mesmo antes da revolução industrial, as sociedades com maior desenvolvimento econômico acreditavam em uma relação de causa e consequência, entre o uso da ciência e da tecnologia com a qualidade de vida das pessoas. Mas é a partir da segunda metade do século XX, baseando-se em uma concepção positivista, que esta visão se agranda e pode ser entendida através do chamado Princípio da Linearidade. Este princípio teoriza que, quanto mais desenvolvemos pesquisa científica, maior o número de projetos de pesquisa aplicada e, quanto mais pesquisa aplicada, mais tecnologia, resultando então em aumento do bem-estar dos indivíduos e maior qualidade de vida da sociedade como um todo (MIRANDA, 2013).

José A. L. Cerezo afirma ainda que, podemos evidenciar esta visão positivista, de forma simplificada, expressa na equação:

\section{+ Ciência $=+$ tecnologia $=+$ riqueza $=+$ bem-estar social}

Para este autor: "A concepção clássica da relação entre ciência, tecnologia e sociedade ainda muito presente em vários campos da academia e da mídia de massa, é uma concepção essencialista e triunfalista" (CEREZO, 1998, p. 1). 
Esta concepção de uma ciência salvacionista e neutra começa a ser abalada por uma série de eventos como: o lançamento das duas bombas nucleares no Japão, o desenvolvimento de novas armas com alto poder de destruição e agressão ambiental, desastres ambientais com resíduos industriais e vazamentos de petróleo. Esta sucessão de fatos, acrescida do embate entre os sistemas capitalista e socialista, dá início, nos países mais desenvolvidos, a uma série de ações promovidas por ambientalistas, ecologistas, pacifistas, alguns cientistas e até políticos, visando o questionamento do uso da ciência e da tecnologia, promovendo assim uma transformação social na forma de compreender a relação entre a ciência e a tecnologia diante da sociedade (CEREZO, 1998).

Desta forma, sem um evento específico ou uma data de fundação, nasce o movimento Ciência - Tecnologia - Sociedade (CTS). Na América do Norte, este início ocorreu com publicações de mídias e movimentações populares, caracterizadas por uma forte veia ativista (MIRANDA, 2013). Na Europa, as primeiras atividades do movimento surgiram na Universidade de Edimburgo, na Inglaterra, nos meados de 1970. Estas ações sugiram no seio dos meios acadêmicos, através de discussões promovidas por cientistas e teóricos, valorizando a ciência como um processo, questionando a origem e as mudanças das teorias científicas (STRIEDER, 2012).

Ainda, buscando as origens do movimento CTS, é possível identificar outra vertente: a Latino Americana. Segundo Vaccarezza (1998), os investimentos governamentais em ciência e tecnologia, na América Latina, ocorreram tardiamente, de forma lenta e gradual, contribuindo para o atraso no surgimento do movimento. Quando este deu seus primeiros passos, suas atividades estavam voltadas para questões envolvendo as políticas públicas relacionadas com a ciência e com a tecnologia e ficou conhecido como Pensamento Latino Americano em CTS (PLACTS).

Linsingen, afirma, quanto às origens do PLACTS, que um dos principais objetivos do pensamento, defendidos por engenheiros e cientistas, era proporcionar o desenvolvimento local do conhecimento científico e tecnológico, visando atender às necessidades da região (LINSINGEN, 2007). Para este autor, esta atitude, necessária frente às influências externas impostas por países mais desenvolvidos, deu ao movimento um caráter diferenciado perante as demais origens.

Com a consolidação desta vertente do movimento, surgem os chamados Estudos CTS na América Latina (ECTSAL) que, segundo Miranda (2013), mesmo não apresentando uma evolução linear, podem ser dividido em três gerações: a primeira, caracterizada pelas discussões promovidas por engenheiros, cientistas e economistas, sem vínculos institucionais; a segunda, já com envolvimento de instituições de ensino superior, com especialistas em áreas de pesquisa e a terceira geração, envolvendo instituições, pesquisadores e pós-graduados em um leque de áreas, dando aos estudos um rigor acadêmico e internacionalizado.

Para Cerezo (1998), falar em CTS é, atualmente, considerar uma vasta gama de programas de colaboração multidisciplinar, com um mesmo núcleo comum, independente da tradição, perpassando por programas filosóficos, sociológicos 
e históricos, enfatizando a dimensão social da ciência e da tecnologia, com os objetivos comuns de oposição à concepção de ciência pura e neutra, crítica à definição de tecnologia como sendo aplicação de ciência e promover a discussão acerca da participação pública na tomada de decisão. Estes desdobramentos podem ser resumidos, segundo este autor, em três campos de ação: o campo das pesquisas acadêmicas, o campo das políticas públicas e o campo da educação.

O enfoque CTS na educação começou no meio universitário, buscando desenvolver uma visão crítica da ciência e da tecnologia. Os primeiros trabalhos escritos sobre ensino com este enfoque surgiram na obra Teaching and Learning about Science and Society, de John Ziman em 1980. Neste livro o autor apresenta uma série de cursos e projetos especiais que consideram sempre a relação do contexto social com o ensino de ciências (ZIMAN, 1980).

Depois desta obra, surgiram outros estudos, apresentando uma grande diversidade nas formas do uso da abordagem, mas que, segundo Bybee (1987), sempre visando à construção de currículos que contemplem estudos de conhecimentos científicos em um contexto relacionado ao educando, possibilitando a participação e a capacidade de discussão acerca do tema. Apresentamos aqui, devido à relevância, as categorias elencadas por Ziman (1994) e as apresentadas por Aikenhead (1994). Segundo Ziman (1994), estas características se completam, dando ao enfoque uma envergadura abrangente e sólida.

As categorias de Ziman (1994) são: o enfoque na aplicação da ciência, visando à compreensão da ciência por meio de suas aplicações, dando relevância à ciência na vida cotidiana; o enfoque vocacional, apresentando a ciência e a tecnologia com intuito de formar um profissional; o enfoque interdisciplinar, propondo o ensino da ciência de forma não segmentada, com uma visão integrada de conhecimento; o enfoque histórico, abordando a ciência e a tecnologia em contexto de mudanças histórico-sociais; o enfoque filosófico, propondo discussões acerca da natureza do conhecimento científico; o enfoque sociológico, abordando ciência e tecnologia a partir das instituições sociais e discutindo como as universidades e indústrias relacionam-se com a sociedade; a problematização, apresentando e procurando soluções diante das questões sociais, considerando causas e consequências envolvidas na relação CTS.

As categorias de Aikenhead (1994) são: a contextualização, visando abordar conteúdos de ciências de forma conectada e integrada com o cotidiano dos alunos; a tomada de decisões, procurando desenvolver a responsabilidade social do educando; o currículo orientado no aluno, considerando-o como cidadão antes de um futuro cientista e por fim, a formação crítica para o exercícios da cidadania.

Segundo Bazzo, Linsingen e Pereira (2003), o movimento CTS no campo da educação tem por principal meta, oferecer possibilidades de inserção da perspectiva CTS em programas de ensino na educação básica e superior, sendo que para Tardif (2002), uma das melhores maneiras de promover desenvolvimento crítico e social junto aos educandos, consiste em oferecermos uma formação profissional adequada, valorizando as práticas e as experiências vivenciadas ao longo de sua 
graduação, promovendo estes acadêmicos, a geradores de novas possibilidades no ensino básico. Ainda nesta linha, Schnetzler (2002) corrobora com esta visão, afirmando que os futuros professores devem ter acesso a uma formação que abarque o conhecimento científico imerso nos enfoques históricos e sociológicos, permitindo assim uma concepção de ciência mais ampla que a tradicional positivista.

\section{METODOLOGIA}

Para identificar, na concepção dos coordenadores de curso, quais as relações entre as licenciaturas analisadas e o enfoque CTS, começamos pela escolha dos sujeitos e da metodologia da pesquisa.

Foram entrevistados três coordenadores de cursos de licenciatura, nas áreas de Ciências da Natureza, de instituições de ensino superior do Norte do Rio Grande do Sul. A escolha dos cursos não foi aleatória, sendo que o critério utilizado baseou-se na observância de um considerável número de egressos destes, que estão atuando na educação básica na referida região.

A pesquisa foi de abordagem qualitativa com natureza básica, por considerar, respectivamente, que prioriza as especificidades e o aprofundamento de uma compreensão e não a representatividade numérica, bem como, por procurar apresentar conhecimento universais, sem compromisso com a aplicação prática e imediata dos resultados. Quanto ao objetivo da pesquisa, podemos classificá-la como exploratória, por buscar "maior familiaridade com o problema, com vistas a tornálo mais explícito ou a construir hipóteses" (GERHARDT E SILVEIRA, 2009, p. 35). O procedimento foi um estudo de caso por se tratar de uma pesquisa com um corpo de sujeitos pertencentes a uma região específica, onde procuramos, sem pretenções de intervenção, entender aspectos e características que consideramos pertinentes com uma perspectiva global (GERHARDT E SILVEIRA, 2009). Para estas autoras, o referido procedimento também é válido para "estudos de casos múltiplos", como por exemplo, diferentes instituições de ensino de uma mesma região. Segundo Robert K. Yin, este procedimento compreende um método que trata desde a lógica e as técnicas de coleta de dados até a análise dos mesmos, sendo que a entrevista constitui, para este autor, a principal forma de coleta de dados (YIN, 2010).

A entrevista, do tipo semiestruturada, contava com 14 questões sobre o tema, conforme a lista 1 e serviram de roteiro para o diálogo, dando liberdade para modificar ou alterar a sequência da conversa, de acordo com o interesse do entrevistado (LÜDKE e ANDRÉ, 2013). Segundo Triviños (2012), o uso desse tipo de entrevista permite que o entrevistado ultrapasse formalidades, construindo sua própria explicação para os fenômenos, enriquecendo a investigação. 


\section{LISTA 1}

1) Quais os objetivos do curso (além do exposto no PPC)?

2) Como a instituição propõe atingir estes objetivos?

3) Em quais momentos do curso os discentes aprendem a ensinar? Como é feito e abordado o ensino da ciência?

4) Quais metodologias e dinâmicas são utilizadas nas aulas que não tem cunho didático?

5) Nas disciplinas de cunho didático, quais são as abordagens propostas para os discentes? Estas aparecem de forma prática ou teórica?

6) Em quais momentos do curso os discentes tem contato, (discussão) com a relação CTS e com os conceitos de ciência, tecnologia e sociedade (cidadania)?

7) Quais as propostas diferenciais ("carro chefe”) do curso no que se refere à formação de professores? (Exemplo: Uso de ferramentas computacionais, uso de materiais alternativos como sucatas, desenvolvimento de projetos interdisciplinares, pesquisa em ensino de ciências, etc).

8) O cientificismo pode ser sintetizado por dois “axiomas": A nível teórico, seria um conhecimento superior a todos os demais. No campo prático, seria a melhor forma de conhecimento para resolver problemas situados desde o campo técnico até o ético. Como o curso trabalha esse conceito com seus discentes? Como pretende-se alterar concepções consideradas erradas?

9) Segundo Auler e Delizoicov, (2001, p.4): "Na concepção tradicional/linear de progresso, ciência e tecnologia, em algum momento do presente ou do futuro, resolverão os problemas hoje existentes, conduzindo a humanidade ao bem-estar social. Duas ideias estão associadas a isso: Ciência e Tecnologia necessariamente conduzem ao progresso e Ciência e Tecnologia são sempre criadas para solucionar problemas da humanidade, de modo a tornar a vida mais fácil." Como o curso trabalha a concepção tradicional e linear da ciência com seus discentes? Em que momentos o curso aborda tais discussões?

10) Das diretrizes de 2015, "Compreende-se a docência como ação educativa e como processo pedagógico intencional e metódico, envolvendo conhecimentos específicos, interdisciplinares e pedagógicos, conceitos, princípios e objetivos da formação que se desenvolvem na construção e apropriação dos valores éticos, linguísticos, estéticos e políticos do conhecimento inerentes à sólida formação científica e cultural do ensinar/aprender, à socialização e construção de conhecimentos e sua inovação, em diálogo constante entre diferentes visões de mundo.” E " No exercício da docência, a ação do profissional do magistério da educação básica é permeada por dimensões técnicas, políticas, éticas e estéticas por meio de sólida formação, envolvendo o domínio e manejo de conteúdos e metodologias, diversas linguagens, tecnologias e inovações, contribuindo para ampliar a visão e a atuação desse profissional." Quando e como esses "valores éticos" e estas "dimensões políticas, éticas e estéticas" são abordadas no curso?

11) "O movimento CTS", "o enfoque CTS nos currículos" e a "abordagem CTS" para gerar aprendizagem, são trabalhados durante o curso? No modo curricular ou em seminários, palestras, cursos extras, disciplinas eletivas, semanas acadêmicas, etc?

12) Em que grau, o curso (colegiado) acredita e defende a ideia, junto aos alunos, de alteração de uma educação bancária, fragmentada e descontextualizada, para uma educação, envolvida com contexto social, propiciando o desenvolvimento crítico em tomada de decisões e a não linearidade da ciência?

13) Quais são suas expectativas, quanto aos resultados, que as mudanças feitas conforme as orientações de 2015 irão provocar? 
14) Na sua opinião: Quais são os fatores e as condições que influenciam na utilização da abordagem ciência - tecnologia - sociedade, na área de ciências da natureza, por parte dos professores da educação básica?

Fonte: Acervo dos Autores.

As entrevistas foram gravadas, de forma individualizada, com o consentimento dos entrevistados, citando-os como C1, C2 e C3, resguardando assim a identificação dos mesmos. Quanto as respostas, estas foram analisadas utilizando-se, para tratamento dos dados, da Análise Textual Discursiva (ATD), conforme Moraes (2003) e Moraes e Galiazzi (2006).

A Análise Textual Discursiva caracteriza-se por ser um procedimento de análise de dados que "transita entre duas formas consagradas de análise na pesquisa qualitativa que são a análise de conteúdo e a análise de discurso" (MORAES E GALIAZZI, 2006, p.118). Este procedimento está dividido, segundo Moraes (2003), em partes, sendo a primeira a desestruturação textual a partir da fragmentação dos dados do corpus. Esta ação é conhecida como unitarização ou desmontagem de texto e o termo corpus, define as produções textuais, "produtos que expressam discursos sobre fenômenos e que podem ser lidos, descritos e interpretados" (MORAES, 2003, p. 194). Esta etapa pode ser dividida ainda, em três momentos: a) fragmentação dos textos; b) reescrita de cada unidade buscando significados mais completos; c) atribuição de nomes para as unidades produzidas. Segundo Moraes e Galiazzi, "A utilização da análise textual discursiva tem mostrado tratar-se de uma ferramenta aberta, exigindo dos usuários aprender a conviver com uma abordagem que exige constantemente a (re)construção de caminhos (MORAES E GALIAZZI, 2006, p. 120).

$\mathrm{Na}$ sequência, procura-se estabelecer as possíveis relações entre diferentes momentos da fala dos entrevistados, etapa chamada de categorização. Nesta, busca-se construir relações entre as unidades de base, reunindo-as em conjuntos denominados de categorias. Por fim, com esta nova compreensão, é possível construir o metatexto resultante, expressando o conjunto de argumentos que, na visão do autor, permitem a compreensão dos fenômenos investigados (MORAES, 2003).

Nestes diálogos, procuramos as relações com a abordagem CTS, separandoas em categorias criadas a priori, baseadas nas principais características do enfoque estudado. São elas: (a) a problematização e a contextualização em currículos voltado para o educando, (b) a interdisciplinaridade e os enfoques histórico, filosófico e sociológico, (c) a inclusão de temas sociais e questões sócio-científicas e (d) a formação cidadã do educando e a valorização da discussão acerca do papel da ciência e da tecnologia.

Após as entrevistas, balizados por estes referenciais metodológicos citados, realizamos, passo a passo, as etapas da ATD, apresentando, na sequência, a análise destes diálogos. 


\section{ANÁLISE DAS ENTREVISTAS}

Regidos e normatizados por princípios comuns, presentes nas Diretrizes Curriculares Nacionais para as Licenciaturas (BRASIL, 2001), e atualizados pelas orientações presentes na Resolução no 2, de $1^{\circ}$ de julho de 2015 (BRASIL, 2015), os cursos possuem um funcionamento muito semelhante quanto ao número de horas, distribuição de carga horária para disciplinas específicas e didáticas, ofertas de estágios e de eventos extra sala de aula.

Todos os entrevistados afirmam que os cursos oferecem um número de créditos superior a $2800 \mathrm{~h}$ (duas mil e oitocentas horas), dividindo estes, em disciplinas que tratam da formação científica específica da área e disciplinas de cunho didático.

Segundo os entrevistados, o curso visa a formação de professores "habilitados para os novos desafios que a educação impõe" (C1), oferecendo desde o primeiro semestre "disciplinas teóricas, experimentais e didáticas, visitas às escolas e encontros em seminários com professores da educação básica" (C1), permitindo assim, "que os acadêmicos começem, desde o início de sua formação, juntamente com o aprendizado científico, a vivenciar o que é a realidade de uma sala de aula" (C2). Para o coordenador C1, a destinação de aproximadamente um terço da carga horária do curso para as cadeiras didáticas, "não implica que somente nestes momentos os alunos aprendem a ensinar, pois estes acadêmicos, mesmo nas aulas teóricas e práticas da sua graduação, estão observando a dinâmica do professor, discutindo formas e metodologias para a abordagem dos conteúdos que estão sendo trabalhados" (C1).

\section{A problematizaçáo e a contextualizaçáo em currículos voltado para o educando}

Conforme os discursos dos estrevistados, seus cursos valorizam muito a contextualização e a problematização em seus currículos, tanto nas disciplinas específicas da área, quanto nas voltadas para as práticas pedagógicas. O coordenador $\mathrm{C} 1$, destaca que: "todos os docentes do curso estão cientes da necessidade de contextualizarmos conteúdos e de localizarmos os estudantes dentro daquilo que é abordado em sala de aula" (C1). Para este entrevistado, devese lembrar também, a capacidade de seu curso em oferecer "multiplos momentos para a inserção do acadêmico no contexto educacional" (C1). Desta forma, o curso está problematizando aqueles conteúdos de caráter didático. Nesta mesma linha, segundo o coordenador $\mathrm{C} 2$, seu curso proporciona, no decorrer da graduação, uma "formação teórico-prática, que visa romper com a racionalidade técnica, para valorizar a prática" (C2). Para este entrevistado, tais momentos ajudam na contextualização e na problematização dos currículos das disciplinas, tanto da área específica, quanto da área de ensino.

Para o coordenador C3, o curso promove a "formação generalizada de conhecimentos específicos e dos fatores humanos relacionados a estes" (C3). 
Este entrevistado afirma ainda que: "na graduação é difícil ensinar a ensinar em todas as cadeiras, pois temos muitos professores que são especialistas em suas áreas específicas e não tem muita relação com o lado pedagógico"(C3). Para C3 ainda, mesmo tendo "esta falta de relação que prejudica a contextualização e a problematização dos conteúdos abordados", ainda "existem duas linhas paralelas, o tempo todo, oferecendo ao acadêmico, numa delas o conhecimento científico, bem positivista, e na outra, os conhecimentos pedagógicos e as discussões acerca das didáticas que deverão ser desenvolvidas" (C3).

As formas com que os cursos problematizam e contextualizam seus conteúdos, segundo os entrevistados, variam conforme a disciplina. Algumas caracterizamse principalmente pela "utilização de laboratórios" (C1) (C2), propondo, com o "uso do método científico" (C1) (C2), a "experimentação paralela à elaboração de modelos que descrevam os fenômenos estudados" (C1), "relacionando diferentes conceitos envolvidos nas situações e nos fenômenos analisados" (C1 e C2). Para os entrevistados C2 e C3, as disciplinas chamadas de "específicas" caracterizamse, além das "aulas tradicionais" (C3), (onde o professor utiliza exemplos em sala de aula para contextualizar), por "práticas de laboratório e estudos de campo" (C2 e C3), "fortalecendo assim, a formação de um professor que entenda onde o conhecimento pode ser aplicado, capacitando-o assim para trabalhar com seus alunos em diversos ambientes" (C3).

Nota-se nas entrevistas, a importância da problematização e da contextualização não só de conteúdos que são trabalhados na graduação, mas também possibilitando a contextualização das metodologias e técnicas didáticas que deverão ser utilizadas para promover as boas condições de ensino. Para Ziman (1980) a problematização é uma das principais características do enfoque CTS e segundo Delizoicov, Angotti e Pernambuco (2009), quando levamos o educando a realizar diversas interações no meio social, saindo da sala de aula, estamos tornando-o um sujeito ativo, imerso em novos objetos de conhecimento. Ainda sobre a problematização, Freire (1977), defende que esta serve como ponto de partida para a construção do conhecimento, promovendo a investigação e a elaboração de ideias, pois quando problematizamos, estamos partindo da realidade concreta de uma situação, buscando identificar o que e como podemos intervir nesse ambiente.

Não está no escopo desta pesquisa a análise das diversas formas de interpretarmos a contextualização, assim, identificamos no discurso destes entrevistados, a concepção de contextualização como sendo o ato de relacionar conteúdos com contextos e situações que aproximem o educando da compreensão do fenômeno estudado. Em alguns momentos das entrevistas, a problematização e a contextualização fundem-se dificultando a interpretação das falas. Sobre esta situação, encontramos nos estudos de Ricardo (2005), disposições que versam sobre a dificuldade em separarmos a contextualização da problematização defendida por Freire. 


\section{A interdisciplinaridade e os enfoques histórico, filosófico e sociológico}

Junto com a contextualização, a interdisciplinaridade é, sem dúvida, um dos termos mais comuns no discurso dos entrevistados. Todos mencionam que seus cursos procuram valorizar a comunicação entre disciplinas, proporcionando para os acadêmicos, "a concepção de temas que vão além das especificidades de cada matéria” (C2).

O coordenador C1 afirma que uma das principais preocupações dos docentes do curso, nas disciplinas de cunho específico da área, volta-se para a abordagem de conteúdos dentro de situações que podem ser analisadas sob o olhar de outros ramos da ciência, permitindo ao educando, "uma melhor compreensão das variáveis a serem consideradas em cada fenômeno abordado". Para C2, a interdisciplinaridade está muito presente nas disciplinas do curso, principalmente nas disciplinas que envolvem práticas de campo e uso de laboratórios.

Ainda é possível identificar nas entrevistas, que todos os cursos analisados acabam incentivando a interdisciplinaridade por meio de ações e projetos extensionistas e de pesquisa, sendo que nestas oportunidades, todos os envolvidos, sejam docentes ou discentes, acabam por envolver-se em temas e questões que transpassam os limites das disciplinas.

A interdisciplinaridade, para Fazenda (2008), não diminui a importância da disciplina, sendo que, para esta autora, esta possui saberes específicos que, quando envolvidos com outras disciplinas, proporcionam a construção do conhecimento de uma realidade e de suas complexidades. Corroborando com este olhar, Bovo (2005) defende que, ao propormos a interdisciplinaridade, saímos da concepção fragmentada que as disciplinas podem deixar, possibilitando uma visão unitária do conhecimento, graças ao diálogo entre estas cadeiras.

Ainda assim, segundo o coordenador C2 e C3, ainda existem docentes que não procuram estas relações entre disciplinas, com argumentos de que "correse o risco de, ao valorizar a contextualização e a interdiciplinaridade, perder o aprofundamento conceitual específico de cada disciplina" (C3). Esta visão opõe-se às concepções de Ziman (1994), que acevera a importância da interdisciplinaridade junto ao favorecimento de uma integração entre as áreas do conhecimento, permitindo uma visão mais ampla e completa dos temas analisados, sem perder em aprofundamento teórico.

Quanto ao enfoque histórico, filosófico e sociológico, os entrevistados afirmam que seus cursos possuem disciplinas específicas que contemplam em suas ementas a história das ciências. Também citam que seus cursos possuem docentes que, por questões peculiares aos estilo e às suas dinâmicas de sala de aula, acabam valorizando sempre o contexto histórico do desenvolvimento das ciências, enquanto que outros não valorizam tal vocação.

Também, de forma unânime na fala dos entrevistados, estes lembram que seus cursos possuem disciplinas comuns a todas as graduações, responsáveis por abordar em seus currículos, análises envolvendo a filosofia e a sociologia das 
ciências. Segundo o coordenador $\mathrm{C} 1$, muitas vezes os acadêmicos não valorizam tais disciplinas, alegando não identificarem a importância destas discussões para sua carreira.

Recorrendo a Japiassu (1979), encontramos considerações apontando que o conhecimento está totalmente envolvido pelo cunho ideológico e filosófico, não podendo ser desligado dos fatores econômicos, religiosos, políticos e extracientíficos. Nesta linha, percebemos que a interdisciplinaridade e os enfoques histórico, filosófico e sociológico, também aparecem no discurso dos coordenadores quando, afirmam que mesmo diante da fragmentação de conteúdos causada pelos currículos e de um quadro cientificista, os cursos avançam para o uso de disciplinas que valorizam a extensão e abordam a história, a filosofia e a sociologia da ciência. Para estes entrevistados, as semanas acadêmicas, os seminários e alguns estudos de campo, criam condições e impõe a necessidade de professores utilizarem a interdisciplinaridade como forma de explicar certos questionamentos.

Neste aspecto, Ziman (1994) defende a necessidade de propormos o ensino das ciências, fazendo uso dos enfoques histórico, filosófico e sociológico. Para este autor, este viés permite que o educando compreenda como a ciência evolui e como esta evolução afeta a sociedade, desmistificando a visão distorcida que existe sobre a atividade científica e favorecendo o entendimento de ciência, como uma atividade humana, sujeita a todos os problemas que permeia qualquer outra construção.

\section{A inclusão de temas sociais e questóes sócio-científicas}

Nesta categoria observamos, diferente das outras duas já abordadas, certas diferenças entre os discursos dos entrevistados. Para C1, apesar do curso valorizar a formação de um sujeito capaz de envolver-se em questões sociais, utilizando o conhecimento científico como aporte para busca de soluções, as disciplinas ainda estão muito focadas no desenvolvimento e no aprendizado dos temas específicos de suas áreas, remetendo dessa forma, uma percepção positivista da ciência.

Porém, para C2 e C3, a maioria de seus docentes valorizam a inclusão de temas e questões sócio-científicas por meio de "estudos de campo" (C3), "visitas às escolas" (C2) e interações junto à comunidade. Seus cursos, segundo os coordenadores, procuram oferecer, nos mais variados momentos, oportunidades onde os discentes aprendem novos conhecimentos específicos de suas áreas, "com os olhos voltados para a comunidade onde esses estão inseridos, visando aplicar seus conhecimentos na busca de soluções para problemas locais" (C2). Tanto o entrevistado C2, quanto o C3, exemplificam tais ações citando que em certas disciplinas de seus cursos, o professor, junto dos discentes, realizam visitas à comunidades regionais, identificando problemas ambientais, como poluição de rios, desmatamentos e recuperação de matas nativas. Segundo estes entrevistados, estas atividades "ensinam e ensinam a ensinar" (C2), considerando que, nestes eventos, "são abordados conteúdos e metodologias de ensino que, no futuro, os licenciandos irão resgatar nas suas práticas docentes. 
Estas iniciativas estão em consonância com as proposições de Auler (2003). Este pesquisador acevera que a educação em Ciências deve, além de outras abordagens, "propiciar a compreensão do entorno da atividade científicotecnológica, potencializando a participação de mais segmentos da sociedade civil" (AULER, 2003, p. 71).

Procurando ainda no discurso dos entrevistados, por depoimentos que nos remetam a esta categoria, identificamos uma certa distinção entre cursos, começando pela matriz curricular. Mesmo que todos os cursos ofereçam disciplinas relacionadas com a ética, com a sociologia e com inovações tecnológicas, somente um dos cursos possui em sua matriz uma disciplina específica, voltada para a relação entre Ciência, Tecnologia e Sociedade e assim, por consequência, conforme o discurso do coordenador deste curso, "existe um comprometimento muito presente entre os docentes do curso e o uso de metodologias que valorizem a aplicação da Ciência e da Tecnologia de forma consciente e ética, junto à sociedade" (C2).

Contudo, apesar deste comprometimento citado, pecebe-se, mesmo em diferentes níveis, baseando-se nas falas dos coordenadores, que os cursos ainda primam por um "cientificismo que valoriza muito o campo técnico" (C1), com uma concepção tradicional de Ciência pura e neutra. Para o entrevistado C3, esta herança está associada a forma com que os docentes do ensino superior aprenderam seus conhecimentos técnicos quando foram graduandos, mantendo assim "o ciclo de se ensinar conforme se aprendeu" (C3).

\section{A formaçáo cidadá do educando e a valorizaçáo da discussáo acerca do papel da ciência e da tecnologia.}

Segundo os entrevistados, os PPCs dos cursos citam, de forma muito clara, o perfil do egresso de cada curso, elencando o compromisso com a formação de um profissional ético e cidadão. Para atingir tais resultados, os cursos possuem em sua matriz curricular disciplinas que não caracterizam-se pelo foco no "fenômeno" (C1) e também não visam "desenvolver metodologias de ensino" (C1). "Estas cadeiras procuram abordar discussões acerca da ética na educação" (C2), história da ciência e sociologia da educação (C1 e C3). "Estas condições implicam em dar ao graduando, visões sobre as diferentes dimensões daquilo que se ensina, procurando também, identificar em que sociedade estes estudantes estarão trabalhando" (C3).

$\mathrm{O}$ coordenador $\mathrm{C} 3$ explica, quanto às metodologias didáticas utilizadas no curso, que "a relação entre ciência e sociedade está como um pano de fundo para todas as disciplinas, sejam de conhecimento específico ou de cunho pedagógico" (C3). Para este participante, "o curso valoriza a ética e cidadania como fatores primordiais na formação do acadêmico, dando incentivo à pesquisa e ao desenvolvimento de equipamentos de fácil acesso a todos" (C3).

Para os coordenadores C1 e C2, o curso também propicia a formação cidadã durante atividades que envolvem a pesquisa e a extensão, como participação em feiras escolares, ações comunitárias, visando, conforme os coordenadores: "utilizar 
o conhecimento científico como forma de exercer a cidadania e melhorar a realidade da sociedade" (C1), e "valorizar a pesquisa e a extensão como forma de melhorar as condições sociais" (C2), admitindo que este conhecimento nos oferece "a melhor forma de vermos a realidade" (C2).

Os três entrevistados ainda abordam que muitos de seus docentes optam em suas aulas por utilizar uma "visão clássica da ciência" (C2), com um "caráter um tanto positivista" (C1), sem dar maior ênfase às questões envolvendo o desenvolvimento do discente cidadão, nem elencando como prioridade as discussões à cerca do papel da Ciência e da Tecnologia diante da sociedade. No entanto, mesmo em diferentes graus, os entrevistados afirmam que os docentes dos cursos tratam o conhecimento científico, como "algo que está sempre em construção"(C1, C2 e C3), evoluindo por meio de "modelos que tentam descrever o funcionamento das partes de um todo" (C1). Ainda sobre a formação cidadã, os entrevistados C2 e C3 reforçam que muitos de seus docentes abordam em suas disciplinas, além dos "conteúdos normais" (C3), discussões acerca da "ética na profissão" (C3) e das "implicações da ciência e da tecnologia na qualidade de vida das pessoas"(C2).

É possível identificar nos discursos dos entrevistados, diversos exemplos que confirmam a intenção dos docentes dos cursos em contribuir com a formação cidadã e com as discussões sobre o papel da sociedade frente aos avanços tecnologicos e científicos: Quando os licenciandos estudam as transformações energéticas, tanto no curso de Física, quanto no curso de Química, aborda-se com a mesma atenção as questões referentes aos impactos ambientais, às vantagens do uso de certas energias e os riscos que as mesmas oferecem. Quando se aborda, no curso de Ciências Biológicas, conteúdos específicos sobre a Botânica ou Ecologia, por exemplo, o professor valoriza além das visitas a campo, questões sobre áreas de riscos ambientais, impactos da urbanização descontrolada e extinção de espécies.

Percebe-se, por meio das entrevistas, que os cursos oferecem em diferentes níveis e momentos, situações promovendo o desenvolvimento cidadão dos discentes e discussões a cerca da relação entre ciência, tecnologia e sociedade. Porém, percebe-se também, que ainda predomina, em muitas disciplinas, o ensino do conhecimento científico neutro e inquestionável, independente da promoção da formação cidadã dos licenciandos e do desenvolvimento da capacidade de tomar decisões responsáveis frente às questões envolvendo a Ciência e a Sociedade. Este perfil, segundo Santos e Mortimer, é fruto da forte influência do cientificismo e de sua função ideológica de dominação, acarretando então, um ciclo educacional onde: "as metodologias científicas levam a uma dominação da natureza com uma eficácia cada vez maior, proporcionando os instrumentos para uma dominação cada vez mais eficiente do homem sobre o homem" (SANTOS E MORTIMER, 2002, p.1).

\section{CONSIDERAÇÓES FINAIS}

É um tanto difícil identificar o quanto o enfoque CTS no ensino da ciência está presente nos cursos de graduação. Seria possível talvez ter um ponto de vista radical e afirmar que não tem relação entre a abordagem e o currículo dos 
cursos? Ou que cursos e enfoque estão totalmente coerentes? Percebemos que, provavelmente, esta dificuldade reside no fato de tais relações estarem diluidas em pequenas doses durante o curso todo, sem que na maioria das vezes exista um momento para abordar o enfoque.

Segundo os coordenadores, os cursos carregam fortes traços do cientificismo, com características de uma educação bancária e fragmentada. Mesmo assim, em menor ou maior escala, todas as disciplinas, através de seus docentes, estão utilizando, direta ou indiretamente, metodologias e abordagens contextualizadas, problematizantes e interdisciplinares, convergindo desse modo com os pressupostos que dão forma à abordagem CTS.

Ao evidenciarmos no discurso dos entrevistados, o cuidado que os cursos têm com as vocações supracitadas, percebemos que estes estão em sintonia com os estudos de Delizoicov, Angotti e Pernambuco (2009). Estes autores afirmam que o professor possui, por excelência, o papel de mediação no processo de aprendizagem do aluno, e sendo assim, possui a potencialidade de contribuir para a formação cidadã que o curso pretende oferecer, incentivando a ética e a responsabilidade social. Ainda corroborando com esta sintonia, Nóvoa (1995) argumenta que, durante a formação do professor, os cursos devem articular a formação científica e as práticas docentes com a constante reflexividade crítica sobre tais práticas, contribuindo assim para a própria identidade do profissional.

Por isso, acreditamos que atingimos o objetivo da pesquisa, ao identificar como e quando os cursos trabalham as vocações do enfoque CTS, mesmo que indiretamente. Percebemos, nestas entrevistas, que os cursos estão em constante evolução, procurando, não só valorizar o conhecimento científico, mas sim, oferecer ao acadêmico a possibilidade de conhecer a sociedade e a realidade das escolas, com suas características que só podem ser percebidas quando vivenciadas.

Conforme o discurso dos entrevistados, identificamos que os cursos utilizam a contextualização, a problematização, a interdisciplinaridade e os contextos históricos, filosóficos e sociológicos no desenvolvimento dos conteúdos. Porém, desvelamos também que dentre os três cursos, existe uma certa diferença entre o quanto estes proporcionam metodologias e abordagens envolvendo a formação cidadã e o papel da Ciência e da tecnologia frente aos contextos sociais.

Por fim, acreditamos que este estudo poderá servir de mote para outros olhares referentes à formação de docentes, possibilitando assim, que no futuro, os estudantes da educação básica tenham professores que consigam despertar a mesma formação crítica, ética e cidadã que o enfoque CTS propõe.

\section{REFERÊNCIAS}

AIKENHEAD, Glein. What is STS science teaching? In: SOLOMON, J.; AIKENHEAD, G. STS education: international perspectives on reform. New York: Teachers College Press, 1994. 
AULER, Décio. Alfabetização Científica-Tecnológica: Um Novo "Paradigma”?. Revista Ensaio - Pesquisa em Educação em Ciências, v.5, n. 1, p. 01-16, mar. 2003.

AULER, Décio; DELIZOICOV, Demétrio. Alfabetização Científico-Tecnológica para quê?; Revista Ensaio - Pesquisa em Educação em Ciências; v. 3; n. 1; 2001.

BAZZO, Walter. Antônio; LINSINGEN, Irlan Von; PEREIRA, Luiz Teixeira do Vale. Introdução aos estudos CTS (Ciência, Tecnologia e Sociedade). Mari, Espanha: OEI (Organização dos Estados Ibero-americanos), 2003.

BOVO, Marcos Clair. Interdisciplinaridade e transversalidade como dimensões da ação pedagógica. Revista Urutágua, Maringá, n. 07, ago-nov, 2005.

BRASIL. Conselho Nacional de Educação. Parecer CNE/CES n 1.304 , Diretrizes Nacionais Curriculares para os Cursos de Física - 2001.

BRASIL. Conselho Nacional de Educação. Parecer CNE/CES no 1.304, Diretrizes Nacionais Curriculares para os Cursos de Química - 2001.

BRASIL. Conselho Nacional de Educação. Parecer CNE/CES n 1.304 , Diretrizes Nacionais Curriculares para os Cursos de Ciências Biológicas - 2001.

BRASIL. Conselho Nacional de Educação. Resolução n $^{\mathbf{0}}$ 2, de $\mathbf{1}^{\mathbf{0}}$ de julho de 2015. 2015.

BYBEE Rodger W. Science Education and the Science-Technology-Society (S-T-S) Theme; Science Education 71(5): 667-683; 1987.

CACHAPUZ, Antonio. Necessária renovação do ensino das ciências; São Paulo: Cortez, 2005.

CACHAPUZ, Antonio; PRAIA, João; JORGE, Manuela. Da Educação em Ciência às Orientações para o Ensino das Ciências: Um Repensar Epistemológico; Ciência \& Educação, v. 10, n. 3, p. 363-381, 2004.

CEREZO, José. Antonio Lopes. Ciencia, Tecnología y Sociedad: El estado de la cuestión en Europa y Estados Unidos, Revista Iberoamericana de Educación. No 18; 1998.

DELIZOICOV, Demétrio; ANGOTTI, José André; PERNAMBUCO, Marta Maria. Ensino de Ciências: fundamentos e métodos. 3. ed. São Paulo: Cortez, 2009.

FAZENDA, Ivani. A. Interdisciplinaridade e transdisciplinaridade na formação de professores. Revista do centro de educação e letras da UNIOESTE, Foz do Iguaçu, v. 10, n. 01, p. 93-103, 2008.

FREIRE, Paulo. Extensão ou Comunicação. 18ª ed. Rio de Janeiro: Paz e Terra, 1977. GERHARDT, Tatiana Engel; SILVEIRA, Denise Tolfo. Métodos de pesquisa / Universidade Aberta do Brasil - UAB/UFRGS e pelo Curso de Graduação Tecnológica 
- Planejamento e Gestão para o Desenvolvimento Rural da SEAD/UFRGS. - Porto Alegre: Editora da UFRGS, 2009.

JAPIASSU, Hilton. Introdução ao pensamento epistemológico. 3 ed. Rio de Janeiro: Francisco Alves, 1979.

LINSINGEN, Irlan Von. Perspectiva educacional CTS: aspectos de um campo em consolidação na América Latina; Ciência \& Ensino, vol. 1, número especial, novembro de 2007.

LÜDKE, Menga; ANDRÉ, Marli. E. D. A. Pesquisa em Educação: Abordagens qualitativas. $2^{\mathrm{a}}$ Ed. Rio de Janeiro: E.P.U., 2013.

MIRANDA, Elisangela Matias. Tendências das Perspectivas Ciência, Tecnologia e Sociedade (CTS) nas Áreas de Educação e Ensino de Ciências: Uma análise a partir de teses e dissertações brasileiras e portuguesas; Tese do Doutorado, Universidade de São Carlos - UFSCar, 2013.

MORAES, Roque. Uma Tempestade de Luz: A Compreensão Possibilitada pela Análise Textual Discursiva; Revista Ciência e Educação; v. 9; n. 2; p. 191-211; 2003.

MORAES, Roque; GALIAZZI, Maria do Carmo. Análise Textual Discursiva: Processo Reconstrutivo de Múltiplas Faces; Revista Ciência e Educação; v. 12; n. 1; p. 117-128; 2006.

NÓVOA, Antonio. O Passado e o Presente dos Professores. In Profissão Professor. Porto: Porto Editora, 1995.

RICARDO, Elio Carlos. Competências, Interdisciplinaridade e Contextualização: dos Parâmetros Curriculares Nacionais a uma Compreensão para o Ensino de Ciências. 2005. 257f. Tese (Doutorado em Educação Científica e Tecnológica). Programa de Pós-Graduação em Educação Científica e Tecnológica. Universidade Federal de Santa Catarina, Florianópolis, 2005.

SANTOS, Wildson Luiz Pereira dos. Educação CTS e cidadania: confluências e diferenças. Amazônia - Revista de Educação em Ciências e Matemática, v.9, n.17, dez. 2012.

SANTOS, Wildson Luiz Pereira dos; MORTIMER, Eduardo Fleury. Uma Análise de Pressupostos Teóricos da Abordagem C-T-S (Ciência-Tecnologia-Sociedade) no Contexto da Educação Brasileira. Ensaio - Pesquisa em Educação em Ciências, Belo Horizonte, v. 2, n. 2, p. 133-162, 2002.

SCHNETZLER, Roseli P. A pesquisa em ensino de química no Brasil: conquistas e perspectivas. Química Nova, v. 25, p. $14-24,2002$.

STRIEDER, Roseline B. Abordagens CTS na educação Científica no Brasil; Tese USP, 2012. 
TARDIF, Maurice. Saberes docentes e formação profissional. Petrópolis, R.J.: Editora Vozes, 2002.

TRIVIÑOS, Augusto N. S. Introdução à pesquisa em ciências sociais: a pesquisa qualitativa em educação. São Paulo: Atlas. 2012.

UNESCO. World Conference on Higher Education: The New Dynamics of Higher Education and Research for Societal Change and Development, Paris, 5-8 Julho 2009.

VACCAREZZA, Leonardo Silva. Ciência, Tecnología y Sociedad: el estado de la cuestión en América Latina; Revista Iberoamericana de Educación, n. 18, p. 1-22, septiembrediciembre 1998.

YIN, Robert. Estudo de Caso: planejamento e métodos. Porto Alegre: Bookmann, 2010.

ZIMAN, John. The rationale of STS education is in the approach. In: Solomon, J.; Aikenhead, G.; STS education: international perspectives on reform. New York: Teachers College Press, 1994.

ZIMAN, John. Teaching and learning about science and society. Cambridge: Cambridge University Press, 1980. 